\title{
Antenatal maternal bereavement and childhood cancer in the offspring: a population-based cohort study in 6 million children
}

\author{
J Li ${ }^{*, 1}, M$ Vestergaard ${ }^{2,3}, \mathrm{C} \mathrm{Obel}^{2,3}, \mathrm{~S} \mathrm{Cnattingus}^{4}, \mathrm{M} \mathrm{Gissler}^{5,6}, \mathrm{~J}$ Ahrensberg $^{3}$ and J Olsen' \\ 'Section for Epidemiology, Department of Public Health, Aarhus University, Bartholins Alle 2, DK 8000 Aarhus C, Denmark; ${ }^{2}$ Section for General Practice, \\ Department of Public Health, Aarhus University, Aarhus, Denmark; ${ }^{3}$ Research Unit of General Practice, Department of Public Health, Aarhus University, \\ Aarhus, Denmark; ${ }^{4}$ Clinical Epidemiology Unit, Department of Medicine, Karolinska Institute, Karolinska, Sweden; ${ }^{5}$ National Institute for Health and \\ Welfare, Helsinki, Finland; ${ }^{6}$ Nordic School of Public Health, Goteborg, Sweden
}

BACKGROUND: Prenatal stress may increase the susceptibility to childhood cancer by affecting immune responses and hormonal balance. We examined whether antenatal stress following maternal bereavement increased the risk of childhood cancer. METHODS: All children born in Denmark from 1968 to 2007 ( N=2 743 560) and in Sweden from 1973 to 2006 (N=3 400212$)$ were included in this study. We compared cancer risks in children born to women who lost a first-degree relative (a child, spouse, a parent, or a sibling) the year before pregnancy or during pregnancy with cancer risks in children of women who did not experience such bereavement.

RESULTS: A total of 9795 childhood cancer cases were observed during follow-up of 68360707 person years. Children born to women who lost a child or a spouse, but not those who lost other relatives, had an average $30 \%$ increased risk of any cancer (hazard ratio (HR) 1.30, 95\% confidence interval (Cl) 0.96-1.77). The HRs were the highest for non-Hodgkin disease (5I2 cases in total, HR 3.40,95\% Cl I.5I-7.65), hepatic cancer ( 125 cases in total, HR 5.5 I, 95\% Cl I.34-22.64), and testicular cancer (86 cases in total, HR 8.52, 95\% Cl 2.03-37.73).

CONCLUSION: Our data suggest that severe antenatal stress following maternal bereavement, especially due to loss of a child or a spouse, is associated with an increased risk of certain childhood cancers in the offspring, such as hepatic cancer and non-Hodgkin disease, but not with childhood cancer in general.

British Journal of Cancer (2012) 1 07, 544-548. doi:I0.1038/bjc.2012.288 www.bjcancer.com

Published online 3 July 2012

(c) 2012 Cancer Research UK

Keywords: childhood cancer; bereavement; prenatal stress; mother; association

Childhood cancer is the second leading cause of death in children in high-income countries (Parkin et al, 2002; Kaatsch, 2010). Almost half of the childhood cancers are diagnosed before 5 years of age (Kaatsch, 2010), highlighting the importance of identifying early-life risk factors (Kimmel, 2005; Anderson, 2006). Only a few risk factors have, however, been established, such as radiation for leukaemia (Giles et al, 1956; Bross and Natarajan, 1972) and cryptorchidism for testicular cancer (Garner et al, 2005), whereas associations between most other factors and childhood cancer risk remain inconclusive (Garner et al, 2005; Eden, 2010). We need to know more about the aetiology of childhood cancer to plan effective prevention strategies (Parkin et al, 2002; Kaatsch, 2010).

The fetal programming concept proposes that environmental factors operating during the peri-conceptional and fetal periods affect the propensity to diseases in adulthood (Gluckman and Hanson, 2006; Harris and Seckl, 2011). Maternal stress during pregnancy may cause excessive production of glucocorticoids and other hormones, which readily passes the placenta (Benediktsson et al, 1997; Gitau et al, 1998). These hormones may have immediate effects on fetal development and long-term effects on health (Kapoor et al, 2006; Davis et al, 2011; Harris and Seckl,

*Correspondence: Dr J Li; E-mail: j|@soci.au.dk

Received 15 March 2012; revised 21 May 2012; accepted 30 May 2012; published online 3 July 2012
2011). Prenatal stress has been related to several diseases related to brain function and chronic degenerative diseases (Davis et al, 2011; Harris and Seckl, 2011). Experimental research has suggested that its effects on endocrine or immune function may also increase the susceptibility to cancer (Reiche et al, 2004; Ekbom, 2006). It remains, however, unknown whether antenatal stress can lead to childhood cancer in humans (Bermejo et al, 2007).

Bereavement by the death of a child or a husband is classified as one of the most stressful events a woman can experience (Skodol and Shrout, 1989; American Psychiatric Association, 1994; Stroebe et al, 2001). Thus, we examined whether maternal stress following bereavement before and during pregnancy increased childhood cancer risk in the offspring. We used a large population-based cohort, based on combined national data from two Nordic countries. We hypothesised that prenatal stress increased the risks of certain cancers, especially those related to the immune and endocrine functions, such as leukaemia or testicular cancer (Reiche et al, 2004; Ekbom, 2006). We further examined whether the death of a child or a spouse was associated with a higher cancer risk in offspring than the death of other relatives (Skodol and Shrout, 1989).

\section{MATERIALS AND METHODS}

This population-based cohort study used data from national registers in Denmark and Sweden, and data collection has been 
described in detail previously (Li et al, 2010). In short, all live-born children and new residents in Denmark and Sweden are assigned a unique civil personal registration number, which is used in the national registration system that includes detailed information on birth, death, and immigration. All children born in Denmark from 1968 to $2007(N=2743560)$ and in Sweden from 1973 to $2006(N=3400212)$ were included and linked to their next of kin (mother, father, siblings, mother's siblings, and mother's parents) by using the personal number. The exposure for this study is defined as maternal bereavement by the death of a child, a spouse/ partner, a parent or a sibling. The exposure time window started from 12 months before the estimated date of conception to the date of child birth, as bereavement before conception may have a longterm detrimental effect on mothers (McEwen, 1998; Gluckman et al, 2008; Harris and Seckl, 2011). Follow-up started at birth and ended at the date of a cancer diagnosis, death, emigration, 14 completed years of age (i.e., before the 15th birthday), or end of follow-up (31 December 2006 in Sweden, and 31 December 2007 in Denmark), whichever came first.

\section{Cancer diagnosis}

The Danish Cancer Registry includes data on all cancer cases in Denmark diagnosed since 1943. Quality of the Danish Cancer Registry is secured by manual coding and validation of data, which provides a high degree of completeness (Gjerstorff, 2011). From 1943 to 1977 the Registry used the modified seventh revision of the International Classification of Disease (ICD-7), and from 1978 and onwards ICD-10 was used for cancer diagnosis (Gjerstorff, 2011). The Swedish Cancer Registry was established in 1958 and contains individual data on all newly diagnosed malignant tumours within Sweden. Tumours are reported to the Swedish Cancer Registry separately by both the diagnosing clinician and the responsible pathologist or cytologist. Nearly $100 \%$ of all diagnosed cancers are reported, with histological verification of $97 \%$ of the tumours. Cancer cases are classified using a 4-digit diagnostic code according to the ICD-7. In addition, a pathological anatomic diagnosis (PAD) is used to define the histological classification of cancers (http://www.socialstyrelsen.se/register/halsodataregister/ cancerregistret/inenglish).

The main outcomes of interest were all incident cancers (ICD-7 codes 104-205, ICD-10 codes C00-97) and several main childhood cancers that have been proposed to have prenatal origin (Reiche et al, 2004; Ekbom, 2006). Specific cancers of interest included leukaemia (ICD-7 204, ICD-10 C91-95), Hodgkin's lymphoma (ICD-7 201, ICD-10 C81), non-Hodgkin's lymphoma (ICD-7 200,202, ICD-10 C82-83), hepatic tumours (ICD-7 155, ICD-10 C22), testicular cancer (ICD-7 178, ICD-10 C62), Wilms' tumour (ICD-7 180 and PAD 886, ICD-10 C64.9), retinoblastoma of the eye (ICD-7 192 and PAD 436, ICD-10 C69.2), and central nervous system tumours (ICD-7 193, ICD-10 C70-71).

\section{Statistical analysis}

Hazards ratios with $95 \%$ confidence limits were estimated using Cox regression models with the PHREG procedure in SAS. Proportional hazard assumption was verified by Kaplan-Meier curves, using PROC LIFETEST procedure. The analyses were stratified by sex of the child, cause of death, type of bereavement, and timing of exposure, which are expected to have a role in the association (Skodol and Shrout, 1989; American Psychiatric Association, 1994; Stroebe et al, 2001). For potential confounders, we included maternal characteristics (Parkin et al, 2002; Kaatsch, $2010)$ (maternal age $(\leqslant 26,27-30, \geqslant 31$ years), parity $(1,2, \geqslant 3)$, education level (low ( $\leqslant 9$ years), middle (10-14 years), and high $(\geqslant 15$ years) ) (available for Swedish data at 1990, 1995, 2000, and 2005, available data for Danish data for 1980-2007), smoking during pregnancy (yes, no) (available 1983-2006 in Sweden and
1991-2007 in Denmark)). We also controlled for child's sex (male, female), birth characteristics (Tower and Spector, 2007; Von Behren et al, 2011), including birth weight ( $<2500 \mathrm{~g}, 2500-3249 \mathrm{~g}$, $3250-3999 \mathrm{~g}, \geqslant 4000 \mathrm{~g})$, gestational age ( $<37$ weeks, $\geqslant 37$ weeks), and Apgar score at $5 \mathrm{~min}(0-6,7-10)$. All data handling and statistical analyses were performed with the SAS version 9.2 statistical software package (SAS Institute, Inc., Cary, NC, USA).

\section{RESULTS}

\section{Population characteristics}

The baseline characteristics of the study population (6143772 children) are shown in Table 1 according to exposure status. Children born to mothers over 30 years of age, mothers with at least three births, mothers with low education, and mothers

Table I Baseline characteristics of the study population ${ }^{a}$

\begin{tabular}{|c|c|c|c|c|}
\hline \multirow[b]{2}{*}{ Variables } & \multicolumn{2}{|c|}{$\begin{array}{l}\text { Exposed cohort } \\
(N=139520)\end{array}$} & \multicolumn{2}{|c|}{$\begin{array}{l}\text { Unexposed cohort } \\
(N=6004252)\end{array}$} \\
\hline & $n(\%)$ & $\begin{array}{l}\text { Person } \\
\text { years }\end{array}$ & n (\%) & $\begin{array}{l}\text { Person } \\
\text { years }\end{array}$ \\
\hline \multicolumn{5}{|l|}{ Sex } \\
\hline Boys & $7 \mid 425$ (5।) & 799073 & 3083078 (5I) & 34268383 \\
\hline Girls & $68095(49)$ & 765933 & $2921153(49)$ & 32527249 \\
\hline \multicolumn{5}{|l|}{ Apgar score at $5 \mathrm{~min}^{\mathrm{b}}$} \\
\hline 1-6 & $|46|(1)$ & 13472 & $50987(1)$ & 461113 \\
\hline $7-10$ & |2839| (93) & | 428407 & 4820664 (92) & 51419896 \\
\hline Unknown & $7765(6)$ & 97654 & I II32600 (8) & 4818647 \\
\hline \multicolumn{5}{|l|}{ Gestational age ${ }^{b}$} \\
\hline <37 Weeks & $8749(6)$ & 91522 & $293656(6)$ & 2948407 \\
\hline$\geqslant 37$ Weeks & $126326(92)$ & | 419911 & $4759095(90)$ & 51288333 \\
\hline Unknown & $2542(2)$ & 28100 & $214060(4)$ & 2462916 \\
\hline \multicolumn{5}{|l|}{ Birth weight ${ }^{b}$} \\
\hline$<2500 \mathrm{~g}$ & $7154(5)$ & 74466 & $23057 \mid$ (4) & 2322122 \\
\hline $2500-3250 \mathrm{~g}$ & $34950(25)$ & 398063 & $1291867(25)$ & $14|1| 440$ \\
\hline $325 \mathrm{I}-3999 \mathrm{~g}$ & $68880(5 \mathrm{I})$ & 776834 & $2631003(50)$ & 28358674 \\
\hline$\geqslant 4000 \mathrm{~g}$ & $24830(18)$ & 271772 & $890216(17)$ & 9351608 \\
\hline Unknown & $1803(1)$ & 18398 & $223155(4)$ & 2555812 \\
\hline \multicolumn{5}{|l|}{ Maternal age } \\
\hline$\leqslant 26$ & $39044(28)$ & 480211 & 2363722 (39) & 28680957 \\
\hline $27-30$ & $39074(28)$ & 450164 & | $74 \mid 535$ (29) & 19220683 \\
\hline$\geqslant 31$ & $6|40|(44)$ & 634616 & | $88779 \mid(3 \mid)$ & 18770340 \\
\hline \multicolumn{5}{|l|}{ Parity $^{\mathrm{b}}$} \\
\hline 1 & 44965 (33) & 499224 & $2201940(42)$ & 23598539 \\
\hline 2 & 51789 (38) & 579917 & | 859081 (35) & 19997833 \\
\hline$\geqslant 3$ & $39389(29)$ & 445209 & $992345(19)$ & 10642374 \\
\hline Unknown & $1474(1)$ & 15184 & $213445(1)$ & 2460910 \\
\hline \multicolumn{5}{|l|}{ Maternal education ${ }^{c}$} \\
\hline Low, $\leqslant 9$ years & 65916 (47) & 800766 & 2245073 (38) & 26945063 \\
\hline $\begin{array}{l}\text { Middle, 10-14 } \\
\text { years }\end{array}$ & $38258(28)$ & 400919 & I $425480(24)$ & 14445228 \\
\hline High, $\geqslant 15$ years & $29062(21)$ & 290018 & $1018674(17)$ & 9496784 \\
\hline Unknown & $6284(5)$ & 73301 & $1315025(22)$ & 15908625 \\
\hline \multicolumn{5}{|c|}{ Maternal smoking during pregnancy ${ }^{d}$} \\
\hline Yes & $22884(19)$ & 252803 & $675522(15)$ & 7316062 \\
\hline No & 64821 (54) & 626318 & $2618413(59)$ & 23706869 \\
\hline Unknown & $51815(28)$ & 685884 & $2710317(26)$ & 35772770 \\
\hline
\end{tabular}

Value is $n$ (\%). Study population includes all children born in Denmark in 1968-2007, born in Sweden in 1973-2006. 'Data available period: 1978-2007 in Denmark, 1973-2006 in Sweden. 'Data available period: 1980-2007 in Denmark, 1973-2006 in Sweden. ${ }^{d}$ Data available period: 199|-2007 in Denmark, 1983-2006 in Sweden. 
who smoked during pregnancy were slightly overrepresented in the exposed cohort.

\section{Overall cancer risk}

Table 2 presents the associations between maternal bereavement and overall childhood cancer risk in offspring. A total of 9795 children were diagnosed with cancer, of which 249 were in the exposed group. Overall, exposed children had a similar risk of cancer (hazard ratio (HR) 1.04, 95\% confidence interval (CI) 0.91-1.18), compared with unexposed children. Children born to mothers who lost an earlier born child or a spouse had a $30 \%$ elevated risk of cancer (HR 1.30, 95\% CI 0.96-1.77), although the association was not statistically significant. Maternal bereavement by death of other relatives was not associated with an increased risk (HR 0.99, 95\% CI 0.85-1.14). Bereavement due to unexpected death of a relative was associated with a similar HR related to bereavement due to other death. We did not observe any significant difference in HRs during the three periods within the exposure time window (12-7 months before conception, 6-0 months before conception, and pregnancy).

Stratification on sex of the child yielded similar findings (data not shown).

\section{The risk of specific childhood cancers}

Table 3 shows results for the specific childhood cancers. For most cancers, the numbers of cases were small, and differences in risk estimates between exposed and unexposed were not statistically significant. The highest risks were observed in children born to mothers who lost an earlier born child or a spouse for nonHodgkin disease (HR 3.40, 95\% CI 1.51-7.65), hepatic cancer (HR 5.51, 95\% CI 1.34-22.64), and testicular cancer (HR 8.52, 95\% CI 2.03-37.73).

\section{DISCUSSION}

This large population-based cohort study revealed increased risks in children born to mothers who experienced a death of a child or spouse during pregnancy or 1 year before pregnancy for some specific childhood cancers, including non-Hodgkin disease, hepatic cancer, and testicular cancer. These excess risks were not dependent on sex of the child, birth characteristics of child (birth weight, gestational age, and Apgar score at $5 \mathrm{~min}$ ), and maternal factors (age, parity, education, and smoking during pregnancy).

\section{Underlying biological mechanisms}

The potential mechanisms between prenatal stress and childhood cancer remain largely unknown (Anderson et al, 2000; Reiche et al, 2004; Ekbom, 2006; Kaatsch, 2010). Excessive stress hormones (mostly glucocorticoids) in pregnant mothers could inhibit the function of $11 \beta$-hydroxysteroid dehydrogenase type 2 (11 $\beta$-HSD2) that serves as the feto-placental 'barrier' to maternal hormones, which would lead to adverse effects on immune and neuroendocrine systems in the fetus (Kapoor et al, 2006; Davis et al, 2011; Harris and Seckl, 2011). Endocrine dysregulation following stress could influence fetal development and potentially programme cancer risk by neuroendocrine-immune interactions (Anderson et al, 2000; Reiche et al, 2004; Ekbom, 2006). The effects of excessive glucocorticoids on HPA axis and immune system could lead to compromised immune responses against cancer cell growth, and promote the initiation and progression of some types of cancer (Anderson et al, 2000; Reiche et al, 2004; Ekbom, 2006). It has also been suggested that such hormones, acting as growth factors, can affect stem cells, introduce malignant transformation, and increase the rate of genetic mutations (Anderson et al, 2000; Reiche et al, 2004; Ekbom, 2006).

\section{Overall cancer risk in offspring and antenatal maternal bereavement}

We observed that prenatal stress exposure following maternal bereavement by the death of any first relative was not associated with an overall increased risk of childhood cancer. This was not unexpected because specific cancers have different aetiologies and it is unlikely that all cancers are affected by stress-induced changes (Anderson et al, 2000; Reiche et al, 2004; Ekbom, 2006). An earlier study indicated that parental death during pregnancy has been associated with an increased risk of several childhood cancers in the offspring (Bermejo et al, 2007), but these findings were based on fewer cases and the comparison group was the general population of children. We observed that the increased cancer risk in offspring was mainly restricted to maternal bereavement by the death of a child/spouse, which is consistent with our prior hypothesis regarding severity of stress (Skodol and Shrout, 1989). The relative risks in relation to different periods within the exposure time window were similar, possibly due to the variances in the sensitive timing windows for different individual cancers (Anderson et al, 2000; Reiche et al, 2004).

Other prenatal factors, such as birth weight or birth order, have been shown to be associated with childhood cancer (Tower and Spector, 2007; Von Behren et al, 2011). Various possible biological

Table 2 HRs for childhood cancer according to exposure (bereavement) status

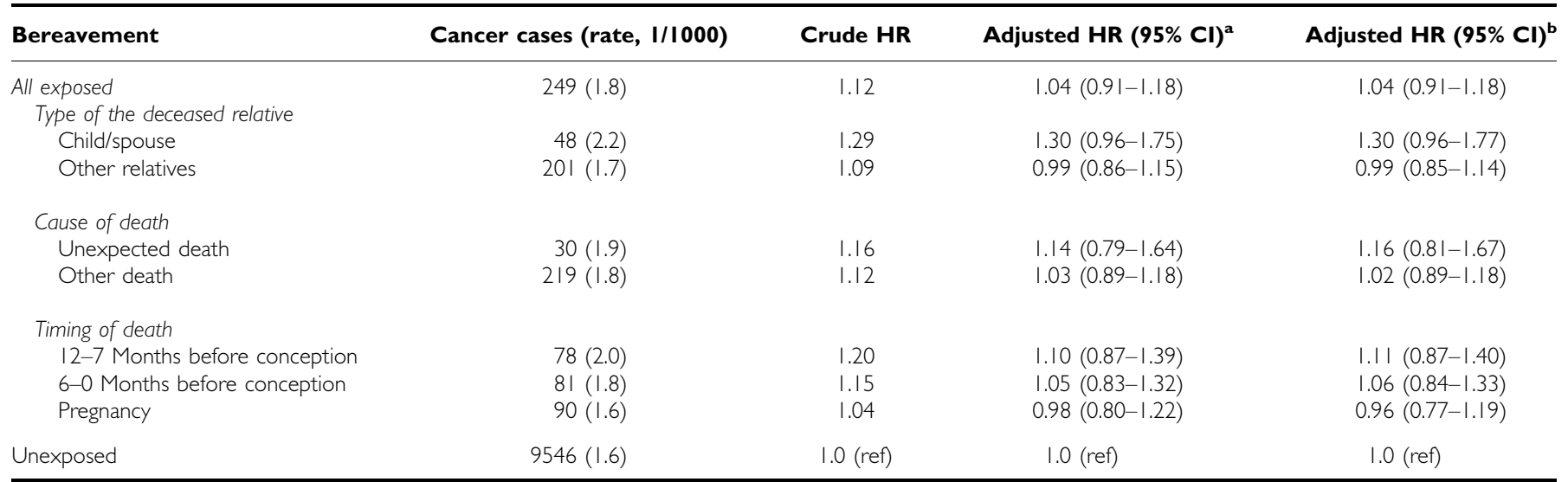

Abbreviations: $\mathrm{Cl}=$ confidence interval; $\mathrm{HR}=$ hazard ratio. ${ }^{a}$ Adjusted for country, sex, maternal factors at child birth (age, education, smoking during pregnancy). ${ }^{\mathrm{b}}$ Adjusted for country, sex, maternal factors at child birth (age, parity, education, and smoking during pregnancy), birth characteristics (low birth weight, Apgar score at 5 min, gestational age), restricted to period when birth characteristics were available (1978-2007 in Denmark, 1973-2006 in Sweden). 
Table 3 HRs for specific childhood cancers according to type of deceased relatives

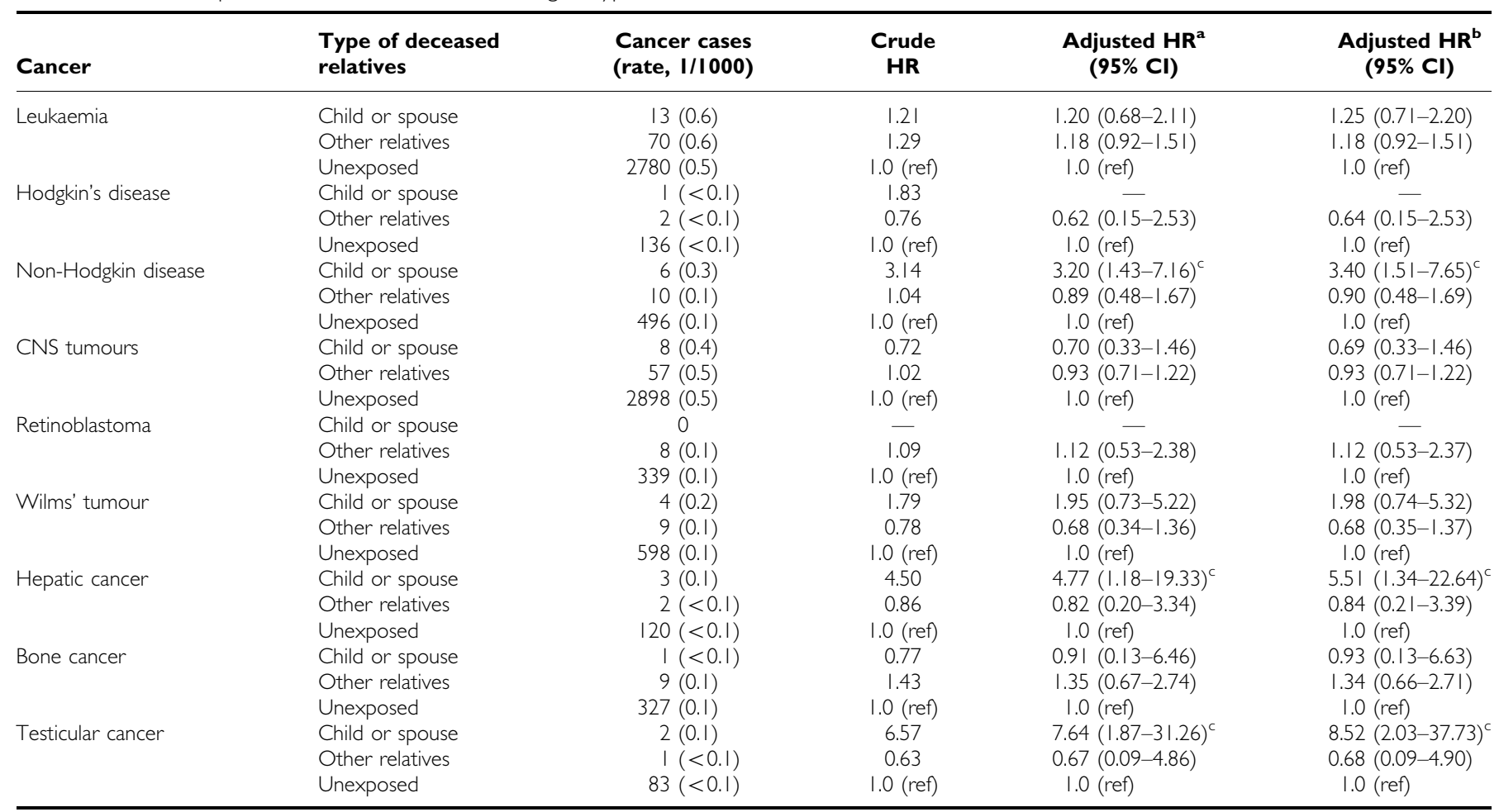

Abbreviations: $\mathrm{Cl}=$ confidence interval; $\mathrm{CNS}=$ central nervous system; HR = hazard ratio. ${ }^{\text {a} A d j u s t e d ~ f o r ~ c o u n t r y, ~ s e x, ~ m a t e r n a l ~ f a c t o r s ~ a t ~ c h i l d ~ b i r t h ~(a g e, ~ e d u c a t i o n, ~ s m o k i n g ~}$ during pregnancy). ${ }^{b}$ Adjusted for country, sex, maternal factors at child birth (age, parity, education, and smoking during pregnancy), birth characteristics (low birth weight, Apgar score at 5 min, gestational age), restricted to period when birth characteristics were available (1978-2007 in Denmark, 1973-2006 in Sweden). ${ }^{c} P<0.05$.

mechanisms have been proposed, including the involvement of insulin growth factors or maternal oestrogen (Milne et al, 2007; Tower and Spector, 2007; Von Behren et al, 2011), which have also been related to prenatal stress (Wadhwa, 2005). As the estimates did not change when we adjusted for these factors, the association between maternal stress exposure and childhood cancer risk in offspring may operate via other pathways (Petridou et al, 1990; Greaves, 2002; Law, 2008).

\section{Risk of specific childhood cancers in offspring and antenatal maternal bereavement}

The associations between prenatal stress following maternal bereavement and risk of some main childhood cancers are noteworthy. So far, studies on fetal origins of childhood cancer have mostly focused on the associations between leukaemia and certain environmental exposures (Linet et al, 2003; Little, 2009). We observed an increased risk of leukaemia (albeit not statistical significant) and non-Hodgkin's lymphoma as also shown in another study (Bermejo et al, 2007). Our findings also support a role of prenatal stress for testicular cancer (Bermejo et al, 2007), consistent with observations on cryptorchidism (Schottenfeld et al, 1980), indicating a role of intrauterine hormonal disturbances (Garner et al, 2005). Although low birth weight (Reynolds et al, 2004), maternal age, and smoking during pregnancy have been proposed to be associated with hepatoblastoma (McLaughlin et al, 2006), the associations are weak and the aetiology of hepatoblastoma remains unclear. Stress hormones, acting as growth factors, might have a role in the pathways (Ekbom, 2006).

\section{Strengths and limitations}

The strengths of our study include the longitudinal design, large sample size, almost complete follow-up, and detailed data on covariates (Frank, 2000). To evaluate the hypothesis of an association between prenatal stress exposure and offspring risk of childhood cancer is difficult due to the rarity of childhood cancer and difficulties in measuring stress exposure. Much of the heterogeneity of previous results might be due to small sample sizes and lack of control for potential confounding by both child and maternal factors. The population-based cohort design based on high-quality data met the above challenges. The design also eliminates the impact of selection and recall bias, which are common problems in case-control studies. The registry system in the Nordic countries provides both a complete case ascertainment and accurate linkage with other data, which allow complete followup with least impact of misclassification error (Frank, 2000; Gjerstorff, 2011).

One limitation is that we lack information on risk factors after birth. We cannot rule out the role of other factors related to bereavement, such as breast feeding and other environmental exposures in later life. Although our cohort is very large, the small numbers of specific cancer cases limited the study power investigating the associations between bereavement and risks of many specific cancer types. Thus, both positive and negative findings should be read with caution as indicated by the wide CIs for the estimates. Another limitation of the study is that we only included exposure to stress due to loss of a close relative, not stress from other sources. Stress could arise from many other situations, such as the death of a close friend, or a serious illness of a next to kin, which may have a similar effect, which will be misclassified as non-exposed in this study. This misclassification is likely nondifferential and would thus have drawn the risk estimates towards unity.

\section{CONCLUSIONS}

Severe antenatal stress exposure due to maternal loss of the closest family member, a child or a spouse, was associated with an 
increased risk of certain childhood cancers in offspring, but not with the childhood cancer in general. Hormonal disturbance may be involved in the observed associations (Reiche et al, 2004; Ekbom, 2006), but our findings may be due to chance and need to be replicated in an independent data source.

\section{ACKNOWLEDGEMENTS}

This work was supported by a grant (to $\mathrm{Dr} \mathrm{Li}$ ) from the European Research Council (ERC-2010-StG no. 260242, the European Union

\section{REFERENCES}

American Psychiatric Association (1994) Diagnostic and statistical manual of mental disorders. 4th edn. American Psychiatric Association: Washington DC

Anderson LM (2006) Environmental genotoxicants/carcinogens and childhood cancer: Bridgeable gaps in scientific knowledge. Mutat Res 608: 136-156

Anderson LM, Diwan BA, Fear NT, Roman E (2000) Critical windows of exposure for children's health: cancer in human epidemiological studies and neoplasms in experimental animal models. Environ Health Perspect 108(Suppl 3): 573-594

Benediktsson R, Calder AA, Edwards CR, Seckl JR (1997) Placental 11 betahydroxysteroid dehydrogenase: a key regulator of fetal glucocorticoid exposure. Clin Endocrinol 46: 161-166

Bermejo JL, Sundquist J, Hemminki K (2007) Risk of cancer among the offspring of women who experienced parental death during pregnancy. Cancer Epidemiol Biomarkers Prev 16: 2204-2206

Bross ID, Natarajan N (1972) Leukemia from low-level radiation:identification of susceptible children. New Engl J Med 287: 107-110

Davis EP, Glynn LM, Waffarn F, Sandman CA (2011) Prenatal maternal stress programs infant stress regulation. J Child Psychol Psychiatry 52: $119-129$

Eden T (2010) Aetiology of childhood leukaemia. Cancer Treat Rev 36: 286-297

Ekbom A (2006) The developmental environment and the early origins of cancer. In Developmental Origins of Health and Disease, Gluckman P, Hanson M (eds) pp 415-425. Cambridge University Press: Cambridge

Frank L (2000) Epidemiology. When an entire country is a cohort. Science 287: 2398-2399

Garner MJ, Turner MC, Ghadirian P, Krewski D (2005) Epidemiology of testicular cancer: an overview. Int J Cancer 116: 331-339

Giles D, Hewitt D, Stewart A, Webb J (1956) Malignant disease in childhood and diagnostic irradiation in utero. Lancet 271: 447

Gitau R, Cameron A, Fisk NM, Glover V (1998) Fetal exposure to maternal cortisol. Lancet 352: 707-708

Gjerstorff ML (2011) The danish cancer registry. Scand J Public Health 39: 42-45

Gluckman PD, Hanson M (2006) Developmental Origins of Health and Disease. Cambridge University Press: Cambridge

Gluckman PD, Hanson MA, Cooper C, Thornburg KL (2008) Effect of in utero and early-life conditions on adult health and disease. $N$ Engl J Med 359: $61-73$

Greaves M (2002) Childhood leukaemia. BMJ 324: 283-287

Harris A, Seckl J (2011) Glucocorticoids, prenatal stress and the programming of disease. Horm Behav 59: 279-289

Kaatsch P (2010) Epidemiology of childhood cancer. Cancer Treat Rev 36: 277-285

Kapoor A, Dunn E, Kostaki A, Andrews MH, Matthews SG (2006) Fetal programming of hypothalamo-pituitary-adrenal function: prenatal stress and glucocorticoids. J Physiol 572: 31-44
Seventh Framework Programme (EU FP7)); and the Nordic Cancer Union; and the NordForsk (070331), the Danish Medical Research Council (projects no. 09-060229, 09-063494, and 09-072986); and the Swedish Council for Working Life and Social Research (grant no. 2010-0092).

\section{Conflict of interest}

The authors declare no conflict of interest.
Kimmel GL (2005) An overview of children as a special populationRelevance to predictive biomarkers. Toxicol Appl Pharmacol 206: 215-218

Law GR (2008) Host, family and community proxies for infections potentially associated with leukaemia. Radiat Prot Dosimetry 132: 267-272

Li J, Vestergaard M, Obel C, Cnattingus S, Gissler M, Olsen J (2010) Cohort Profile: the Nordic Perinatal Bereavement Cohort. Int J Epidemiol 40: 1161-1167

Linet MS, Wacholder S, Zahm SH (2003) Interpreting Epidemiologic Research: lessons from studies of childhood cancer. Pediatrics 112: 218-232

Little MP (2009) Cancer and non-cancer effects in Japanese atomic bomb survivors. J Radiol Prot 29: A43-A59

McEwen BS (1998) Protective and damaging effects of stress mediators. New Engl J Med 338: 171-179

McLaughlin CC, Baptiste MS, Schymura MJ, Nasca PC, Zdeb MS (2006) Maternal and infant birth characteristics and hepatoblastoma. Am J Epidemiol 163: 818-828

Milne E, Laurvick CL, Blair E, Bower C, de KN (2007) Fetal growth and acute childhood leukemia: looking beyond birth weight. Am J Epidemiol 166: $151-159$

Parkin DM, Whelan S, Ferlay J, Thomas DB (2002) Cancer Incidence in Five Continents VIII. IARC Scientific Publications: Lyon, France, Ref Type: Serial (Book, Monograph)

Petridou E, Panagiotopoulou K, Katsouyanni K, Spanos E, Trichopoulos D (1990) Tobacco smoking, pregnancy estrogens, and birth weight. Epidemiology 1: 247-250

Reiche EMV, Nunes SOV, Morimoto HK (2004) Stress, depression, the immune system, and cancer. Lancet Oncol 5: 617-625

Reynolds P, Urayama KY, Von Behren J, Feusner J (2004) Birth characteristics and hepatoblastoma risk in young children. Cancer 100: 1070-1076

Schottenfeld D, Warshauer ME, Sherlock S, Zauber AG, Leder M, Payne R (1980) The epidemiology of testicular cancer in young adults. Am J Epidemiol 112: 232-246

Skodol AE, Shrout PE (1989) Use of DSM-III axis IV in clinical practice: rating etiologically significant stressors. Am J Psychiatry 146: 61-66

Stroebe MS, Stroebe W, Hansson RO, Schut H (2001) Handbook of bereavement research: Consequences, coping, and care. American Psychological Association: Washington DC

Tower RL, Spector LG (2007) The epidemiology of childhood leukemia with a focus on birth weight and diet. Crit Rev Clin Lab Sci 44: 203-242

Von Behren J, Spector LG, Mueller BA, Carozza SE, Chow EJ, Fox EE, Horel S, Johnson KJ, McLaughlin C, Puumala SE, Ross JA, Reynolds P (2011) Birth order and risk of childhood cancer: A pooled analysis from five US States. Int J Cancer 128: 2709-2716

Wadhwa PD (2005) Psychoneuroendocrine processes in human pregnancy influence fetal development and health. Psychoneuroendocrinology 30: 724-743

This work is published under the standard license to publish agreement. After 12 months the work will become freely available and the license terms will switch to a Creative Commons Attribution-NonCommercial-Share Alike 3.0 Unported License. 